\title{
PERCEPÇÕES EMPÍRICAS SOBRE O CONTROLE JUDICIAL DE POLÍTICAS PÚBLICAS
}

\section{Lilian Balmant Emerique ${ }^{1}$}

\section{Resumo}

O presente artigo trata do mapeamento de aspectos empíricos sobre a atuação do Superior Tribunal de Justiça (STJ) no exercício do controle judicial de políticas públicas, buscando fazer um diagnóstico conciso do estado da arte no âmbito do Poder Judiciário. A metodologia utilizada consistiu no levantamento e análise empírica dos julgados no STJ catalogados como pesquisa pronta sobre "controle judicial de políticas públicas" entre os anos de 2011 e 2014, construindo banco de dados a partir do exame das decisões e buscando o viés teórico que serviu para fundamenta-las identificado preferencialmente na matriz teóricaneoconstitucionalista.

Palavras-chave: controle judicial, políticas públicas, análise empírica, neoconstitucionalismo, Superior Tribunal de Justiça (Brasil).

\section{INTRODUÇÃO}

O tema do controle judicial de políticas públicas há algum tempo ocupa espaço dentro dos debates travados na doutrina e na jurisprudência, admitindo posições plurais face às controvérsias suscitadas e uma gama variada de argumentos contrários e favoráveis à atuação do Poder Judiciário na matéria.

Frente a um cenário de ricas contribuições de autores e de operadores jurídicos ao assunto, ficam em aberto diálogos sobre possíveis novos horizontes de abordagem que ainda poderiam ser delineados e que aspectos poderiam ser explorados e que corresponderiam a plausíveis lacunas ou pontos a serem elucidados ou cujo tratamento e arguição careceriam deamplificação.

A controvérsia expõe interfaces com várias frentes de discussões reveladoras da interdisciplinariedade, tais como: papel do Estado, Separação de Poderes, Teoria da Justiça, construção e análise de políticas públicas, gestão pública, constitucionalismo social, orçamento público, federalismo, dentre outros. A complexidade temática impõe um tratamento menos superficial do alcance das análises para evitar cair em generalizações e em lugares comuns perfilhados por discursos jurídicos retóricos e sem base empírica que lhes sirva de suporte.

\footnotetext{
${ }^{1}$ Pós-doutora em Ciências Jurídico-Política. Professora Adjunta da faculdade de Direito da Universidade Federal do Rio de Janeiro, sendo membro permanente do corpo docente do Programa de Pós-Graduação em Direito. E-mail: lilamarcia@gmail.com vol.09, nº. 02, Rio de Janeiro, 2016. pp. 670-694 
Boa parte das polêmicas em torno do controle judicial de políticas públicas está conectada com direitos sociais. Estes, por sua vez, estão dispostos no art. $6^{\circ}$ da Constituição da República Federativa do Brasil de 1988 e muito do seu conteúdo se desenvolve no Título VIII, dedicado à ordem social. A doutrina jurídico-constitucional tem considerado os desdobramentos dessas normas na estruturação de um Estado Democrático de Direito. Cumpre lembrar que os direitos sociais são autênticos direitos fundamentais expressos na Constituição e, por este motivo, possuem todas as prerrogativas inerentes à sua condição ou ao status decorrente de sua natureza fundamental, sempre que o enunciado da norma constitucional permitir tal inflexão em toda sua amplitude. Contudo, nem sempre os mesmos são creditados adequadamente e/ou todo tipo de obstáculos são suscitados comprometendo sua eficácia eaplicabilidade.

Diante de uma conformação constitucional profícua de direitos fundamentais, o Poder Público se vale das chamadas Políticas Públicas. Todavia, a realidade da sociedade brasileira indica que as políticas públicas ou existem, porém são insuficientes para atenderem a demanda social, ou nem mesmo chegam a existir. A construção de políticas públicas engloba desde a perquirição sobre a extensão do núcleo dos direitos sociais, até a disponibilidade de recursos financeiros para implementá-las. Enfim, inúmeros entraves políticos e jurídicos dificultam o seu desenvolvimento.

As práticas de inclusivas promovidas por meio de políticas públicas que, geralmente, são de competência ou atribuição a ser executada pela Administração Pública (diga-se, Poder Executivo), são atingidas (ou adiadas), porque em muitos casos são desviadas dos seus objetivos. A falta de conhecimento sobre direitos fundamentais é um fator que contribui para que estas não sejam reconhecidas como forma de cumprimento de deveres e realização de direitos passíveis de serem exigidos na esfera do PoderJudiciário.

Frequentemente o paternalismo e assistencialismo perpassam as ações do Estado e da sociedade brasileira, pois, o acesso à alimentação, moradia, saúde, educação, cultura, ao lazer, entre outros, ainda não são reconhecidos plenamente como direitos fundamentais, ao contrário, é comum que os direitos sociais sejam confundidos como favor político, caridade ou privilégio de certas pessoas em detrimento de outras.

Devido à carência social de prestações estatais, ou inclusive pela sua omissão, o Poder Judiciário é acionado para decidir sobre demandas relacionadas aos direitos sociais. A expectativa social apoia-se no entendimento de que juízes e tribunais garantam a fruição de direitos fundamentais, especialmente os de natureza prestacional, contudo, por outro lado, a ausência de critérios claros e objetivos geralmente geram dúvidas na decisão e dão espaço para que alguns sejam contemplados com resultados favoráveis nas suas ações e outros, em razão de interpretações diferenciadas, não consigam obter soluçãosemelhante.

O Poder Judiciário diuturnamente é cobrado na promoção de inclusão social, uma vez que se trata de um poder com maior autonomia e independência em relação aos demais poderes. O sujeito, diante da 
prerrogativa constitucional de inafastabilidade da jurisdição, procura o órgão jurisdicional na esperança de resguardar ou aplicar sua pretensão ou direito em juízo. A atuação nas instâncias judiciais é polêmica e alvo de críticas que aqui, não pretendemos enquadrar, mas reconhecemos que alguns excessos são cometidos e merecem uma análise mais depurada da doutrina em relação aos níveis de cabimento do controle judicial sobre as políticas públicas, especialmente aquelas relacionadas aos direitos sociais.

De fato, isto não aparta a necessidade de que sejam rebatidas as omissões estatais perante direitos fundamentais que inibem a aplicabilidade e o respeito aos direitos sociais. Em resumo, medidas concretas de política devem ser tomadas para que sejam efetivados valores substanciais, inafastáveis as pessoas, por força dos princípios e dos objetivos fundamentais previstos na Constituição de 1988.

O debate sobre o controle judicial de políticas públicas não pode ser processado apenas com compreensões de ordem jurídica, porque basicamente a questão enverada por searas marcadas pela multiplicidade de saberes (interdisciplinariedade e transdiciplinariedade). A complexidade fica ainda mais evidente quando se constata que nenhuma das matérias específicas que caracterizam o estudo das políticas públicas se acha definida com precisão e de modo unívoco, a começar pela própria definição de políticas públicas ou policy.

Assim, o presente estudo não tem a pretensão de inaugurar novos campos de análise e nem se traduzir em inovações que resultem em mudanças profundas nos paradigmas de abordagem da temática. O propósito aqui empreendido consiste em, tão somente, fazer um levantamento sucinto do estado da arte quanto ao tratamento dado à matéria do controle judicial de políticas públicas, através de diagnóstico empírico sobre a jurisprudência do Superior Tribunal de Justiça brasileiro.

\section{DIREITO COMO INSTRUMENTO DE CONTROLE DAS POLÍTICAS PÚBLICAS}

A correlação entre controle de políticas públicas pelo Poder Judiciário é fonte de tensão permanente. No campo do direito, os lineamentos traçados em épocas passadas tendencialmente apontavam para direções opostas, apartando pela visão tradicional do direito administrativo, o exame do mérito do ato administrativo produzido pelo Poder Executivo por parte do Poder Judiciário. Esta tendência foi perdendo sua força com o passar dos anos, especialmente após a Constituição de 1988 e a crescente judicialização das políticas públicas.

Entretanto, a simples aceitação da conjectura de exercício do controle judicial das políticas públicas não resolve os pontos de tensão na interface entre direito e políticas públicas, porque persistirão impasses quanto ao momento em que o controle deverá ser exercido e sobre a extensão e limites em cada caso, se em caráter preventivo, concomitante e sucessivo à implementação dos programas públicos sociais e econômicos, ou seja, em três momentos distintos: na formulação, na execução ou na avaliação das políticaspúblicas. 
A admissão do controle também não dá uma resposta de pronto ao problema da medida judicial aplicável, porque, a título de controlar a execução de uma política pública, os juízes anulam os atos administrativos praticados, e, inclusive, em certas decisões, alteram o seu conteúdo, por meio de uma atividade substitutiva, gerando medidas de cunho prático a partir de direitos previstos de modo genérico na Constituição. A intervenção judicial deixa de ter uma natureza invalidatória exclusiva, passando a assumir uma função substitutiva, muitas vezes, criticada pelos seus efeitos.

As tensões demonstram a persistência da necessidade de aprofundamento da discussão da matéria sem se contrapor a ideia de que os limites da intervenção judicial na construção e execução das políticas públicas dependerá, pelo menos em parte, da concepção que o próprio Judiciário formula ou formulará sobre a extensão de sua própria jurisdição, a partir da interpretação da Constituição como umtodo.

Também é emblemática a discussão em torno do controle judicial das políticas públicas e o Princípio da Separação dos Poderes, realocando a matéria sob um viés que ultrapassa as condicionantes históricas que figuraram nas fases teóricas precedentes sobre este princípio e incorporando análises contemporâneas. que buscam rever marcos conceituais passados.

A resposta não pode ser ingênua, pois as implicações da aceitação de um modelo ilimitado de jurisdição dos direitos sociais e de implementação das políticas econômicas pelo Judiciário, pode conduzir a resultados deletérios na sociedade, inclusive com efeitos reversos sobre a própria imagem do poder, questionada em sua capacidade institucional de atuar nestas questões. Principalmente, em relação à produção de resultados políticos, que deixam o lastro sobre pontos a serem analisados em torno da ideia de dever e não com base na visão mais convencional articulada em torno da ideia de poder. Tendo em vista que no exercício da função pública o sujeito exercita um poder, contudo o faz em proveito alheio, e opera não porque queira ou não queira, mas porque tem o dever de fazê-lo (aspecto republicano). Assim, o "poder discricionário” tem que ser unicamente o cumprimento do dever de alcançar a finalidade legal. "Só assim poderá ser corretamente entendido e dimensionado, compreendendo-se, então, que o que há é um dever discricionário, antes que um "poder" discricionário. ” (BANDEIRA DE MELLO, 1998, p. 15)

Não obstante seja relevante admitir que políticas públicas demandem certo grau de liberdade ou de margem de escolha e adaptação dos agentes públicos, o tratamento da discricionariedade pela doutrina jurídica brasileira ainda parece se fixar mais intrinsecamente na busca do que são atos vinculados ou discricionários, ou com o desenho de critérios para disciplinar a liberdade de escolha do agente público e, em função disso, não se verificou a importância do engajamento no processo decisório face aos verdadeiros constrangimentos que a realidade coloca. Em consequência, perdura a visão entorpecida pelo diálogo do "isso pode/isso não pode", sem que de fato exista um debate sobre "como se pode" atender objetivos na administração pública. Em parte, este 
problema resulta do temor dos gestores públicos, juristas ou não, de que as razões práticas e funcionais que justificaram essa ou aquela decisão possam ser questionadas por órgãos de controle, como tribunais de conta, controladorias e Poder Judiciário (COUTINHO, 2013, p. 188).

Portanto, o foco de compreensão do direito administrativo precisa ser revisado para também poder servir como um aliado a mais, uma ferramenta útil para implementação de políticas públicas, e isto requer um arcabouço jurídico minimamente flexível, aberto a experimentações, a revisões e a incorporação de aprendizados, sem olvidar da dimensão de controle e restrição que ele exerce, via prestação de contas adequada e controle democrático, porém sem construir apologias que apenas ressaltem este aspecto que, por si só, é necessário.

\section{ANÁLISE EMPÍRICA DO CONTROLE JUDICIAL DE POLÍTICAS PÚBLICAS NO SUPERIOR TRIBUNAL DE JUSTIÇA}

Na presente etapa mapearemos aspectos empíricos sobre a atuação do Superior Tribunal de Justiça (STJ) no exercício do controle judicial de políticas públicas, buscando fazer um diagnóstico conciso do estado da arte no âmbito do Poder Judiciário, visto que este acolhe processos provenientes dos tribunais nas unidades da federação em índole recursal e também tem competência para atuar em primeira linha em alguns tipos de processos. $^{2}$

As referências que aqui serão apresentadas têm por objetivo principal estabelecer um diagnóstico de natureza qualitativa, sem, contudo, desprezar dimensões quantitativas na abordagem efetuada, quando for pertinente.

\section{Metodologia}

A metodologia utilizada na investigação consistiu em levantamento no sítio eletrônico do STJ, no diretório designado como pesquisa pronta, com o descritor "Controle judicial de políticas públicas", dos casos que receberam tal enquadramento. ${ }^{3}$ Em seguida, definiu-se como espaço temporal da pesquisa os julgamentos efetuados pelo STJ entre os anos de 2011 e 2014, o que conduziu a um universo de 35 acórdãos, muito embora

\footnotetext{
${ }^{2}$ Reconhecemos que nem todas as questões de controle judicial de políticas públicas são objeto de análise pelo STJ, há casos em que Tribunais de Justiça estaduais e instâncias judiciais inferiores apreciam em caráter definitivo demandas desta natureza. Contudo, optamos pelo estudo no STJ por possuir uma plataforma de consulta mais completa e confiável e por permitir um estudo com abrangência nacional.

${ }^{3}$ www.stj.jus.br/SCON/jurisprudencia/toc.js acessado em 30/01/15. O site do STJ é normalmente indicado como melhor equipado para pesquisa jurisprudencial e mais confiável para levantamentos empíricos. Na ocasião a pesquisa identificou 86 acórdãos com julgamento efetuado entre os anos de 1999 e 2014, com base na pesquisa pronta fornecida pelo próprio site, com o descritor controle judicial de políticas públicas. Todavia, nem todos os acórdãos referenciados realmente tratavam de questões relacionadas ao controle judicial de políticas públicas e, em alguns casos, o assunto abordado apenas indiretamente, em segundo plano representavam discussões em torno de políticapública.
} 
nem todos versassem sobre o tema investigado, resultando enfim em 31 acórdãos sobre controle judicial de políticas públicas, dos quais alguns punham foco sobre outras matérias e somente de forma indireta tratavam de políticas públicas. A maior parte das ações originárias são Ações Civis Públicas, em seguida estão os mandados de segurança e depois as ações ordinárias, porém nem sempre há uma referência ao tipo de ação originaria julgada pelo STJ, uma vez que o recurso não faz menção direta ao caso de origem.

A escolha da jurisprudência do STJ deveu-se ao fato desta Corte absorver mais proximamente demandas provenientes dos órgãos de Justiça estaduais, permitindo identificar aspectos suscitados sobre a temática vindos de várias frentes do judiciário brasileiro e mostrando o perfil das decisões em órgão superior.

Após o levantamento foi construído um banco de dados para classificar os acórdãos selecionados, julgados entre os anos de 2011 a 2014, constando as seguintes informações de cada processo: número do processo; recorrente/agravante; recorrido/agravado; ano de entrada no STJ; data do julgamento; decisão; legislação; assunto; argumentos teóricos; tipo de ação de origem; órgãojulgador.

$\mathrm{Na}$ fase subsequente, efetuamos o tratamento dos dados coletados e construímos tabelas e outros elementos gráficos como suporte para a análise e a crítica, a partir das informações recolhidas.

\section{Analise dos julgados}

\section{Quanto ao tempo entre a chegada do processo e o seu julgamento pelo STJ}

Observou-se que dos 31 processos analisados 22 deles foram julgados em até um ano desde a sua chegada, ou seja, 70,96\%, 03 foram julgados em até dois anos (9,67\%) e 06 foram julgados em até três anos $(19,34 \%)$. Os dados revelam que em termos de medida temporal os processos não estiveram tempo excessivo no STJ, demonstrando uma preocupação de não causar embaraços maiores ao desfecho da demanda.

Não obstante, há que se considerar que este tempo processual não reflete o tempo total desde a propositura da ação, o que pode ser complicado em termos de análise de políticas públicas, visto que estas são, em grande parte, componentes de escolhas políticas circunscritas à agenda cambiante em cada mandato. O tempo do processo judicial não equivale em sua acepção ao tempo no universo político, cuja dinâmica e mecanismos de transformação de um problema em uma questão de política pública não conta de igual forma, principalmente quando tal política pública ainda se sujeita aos trâmites legislativos, o que traz uma complexidade adicional.

Daí se destacar que a judicialização de políticas públicas em dado momento, por razões bastantes plausíveis devido às ilicitudes ou omissões administrativas na matéria questionada, pode não configurar igual descaso no momento em que a lide chega ao seu desfecho final. Isto porque, podem existir autênticos esforços, 
nem sempre suficientes, para tentar reduzir ou mesmo debelar o impacto do problema, ou se pode concluir que ao longo do processo o problema intensificou-se pelo investimento deficitário ou focalizado em outrasáreas.

Enfim, neste ponto, o Poder Judiciário sempre terá diante de si um obstáculo operacional para avaliação devido sua capacidade institucional diferenciada, o que não inviabiliza a decisão, porque o julgamento não se traduz em termos de mensuração sobre decisões políticas, seus acertos e desacertos, mas na análise do direito que serve de base para a ação proposta.

\section{Tipo de ação/recurso apreciado pelo STJ}

Dos 31 julgados analisados, 12 são recursos especiais; 14 são agravos regimentais; 02 são mandados de segurança; 02 são recursos em mandado de segurança; e 01 trata-se de embargos de declaração no recurso especial.

\section{$\underline{\text { Recorrente/ agravante e recorrido/agravado }}$}

Existe um leque variado de recorrentes/agravantes nos julgados analisados sendo: 10 de pessoas físicas; 01 de pessoa jurídica; 04 de concessionárias; 03 de autarquias; 01 do Ministério Público Federal; 03 do Ministério Público dos Estados; 02 da União; 05 dos Estados-membros e 02 deMunicípios.

Em relação aos recorridos/agravados nos julgados selecionados existem: 04 de pessoas físicas; 02 de Ministros; 03 de concessionárias; 02 de autarquias; 02 do Ministério Público Federal; 07 do Ministério Público dos Estados; 01 da União; 04 dos Estados e 06 de Municípios.

Há uma autêntica pulverização dos atores litigantes e que impulsionam o processo aos níveis recursais mais altos visando reverter decisões das instâncias inferiores, mesmo que tenham pouca hipótese de alcançar sucesso em seus recursos.

\section{Decisão}

Nas decisões proferidas pelo STJ nos casos referentes ao controle judicial de políticas públicas apreciadas entre os anos de 2011 e 2014, encontram-se as seguintes posições: 01 caso de extinção do processo por unanimidade (3,225\%); 04 de procedência total por unanimidade (12,9\%); 04 de procedência parcial por unanimidade (12,9\%); 01 procedência total por maioria (aproximadamente 3,225\%); 20 de improcedência total por unanimidade (64,5\%); 01 de improcedência total por maioria(3,225\%).

Existe uma ampla maioria de casos em que o STJ decidiu pela improcedência total por unanimidade, confirmando decisões precedentes. Os julgados sobre controle judicial de políticas públicas envolvem em sua 
maioria órgãos da administração pública direta e indireta, que contam com duplo grau de jurisdição e soma-se a isso a cultura do processo e as complexidades em torno da matéria, que podem acarretar a litigância prolongada até as cortes mais altas, ainda que o veredicto corrobore com as decisões proferidas em instânciasinferiores. ${ }^{4}$

Neste ponto fica a crítica aos excessivos recursos admitidos na legislação processual brasileira que dão azo ao delongar das questões na Justiça e, por mais que os órgãos jurisdicionais se esmerem para ofertar uma prestação jurisdicional em tempo razoável, sem a redução na legislação dos meios recursais possíveis durante a litigância o processo possivelmente percorrerá vários níveis na Justiça até o seu trânsito emjulgado.

Importa salientar que o processo deve ser um instrumento útil para realização da Justiça, contudo, é comum constatar que nos litígios nos quais a administração pública (direta ou indireta) figura como parte são os mais lentos e onerosos na prestação jurisdicional.

A expressão “acesso à Justiça”, embora polissêmica se associa ao seu propósito elementar de permitir que pessoas possam reivindicar/defender seus direitos e/ou resolver seus litígios (judiciais ou administrativos) sob os auspícios do Estado, sem perder de vista a igualdade de acesso a todos indistintamente e a produção de resultados individual e socialmente justos (CAPPELLETTI e GARTH, 1988). Portanto, a questão da equidade é um elemento significativo no tratamento da matéria de acesso à Justiça e é um requisito fundamental para garantir e não apenas proclamar direitos de todos.

A compreensão de acesso à Justiça que se tem em mira não se circunscreve a via judicial, a mera possibilidade de acesso ao Poder Judiciário (instituição) para obtenção de uma resposta jurisdicional, o direito fundamental expresso na garantia de acesso à Justiça implica no reconhecimento da necessidade de promoção do acesso à ordem jurídica justa em todos os níveis de atuação estatal, portanto, em todas as esferas de poder incluindo o Executivo e o Legislativo.

Este entendimento ganha espaço na doutrina, conforme se observa: "problemática do acesso à Justiça não pode ser estudada nos acanhados limites do acesso aos órgãos judiciais já existentes. Não se trata apenas de possibilitar o acesso à Justiça enquanto instituição estatal, e sim de viabilizar o acesso à ordem jurídica justa. ” (WATANABE, 1988, p. 129).

O acesso à ordem jurídica justa pode ser alcançado pelo Judiciário na solução satisfatória dos conflitos de interesse que aprecia; pela atividade legislativa justa e correta e pela atuação efetiva e eficiente da Administração Pública nos termos da lei, para que ela não dê ocasião aos conflitos de interesse com o cidadão por não estar cumprindo as normas legais impostas pelo próprio Estado e pela Constituição.

\footnotetext{
${ }^{4}$ Em vários julgados foram observados problemas resolvidos com base em argumentos meramente processuais, cujo conteúdo refletia incompetência do STJ para julgar a questão ou o não preenchimento de requisitos processuais para o cabimento da ação/recurso.
} 
O reconhecimento dos limites da jurisdição na consumação dos objetivos a que se propugna exige do Estado o investimento em soluções, dentro e fora do Judiciário, dirigidas a realizar o direito de acesso à Justiça, esse mesmo intento também tem implicações especiais para a AdministraçãoPública.

Na perspectiva de efetivar o acesso à Justiça é necessário saber diferenciar litígios no que concerne a sua complexidade, montante envolvido na controvérsia, a importância social do caso e, por último, a relevância do elemento temporal dispendido na solução do caso (casos que exigem maior celeridade). Também há diferenças entre parte envolvidas no processo, há situações que abarcam partes que manterão relações ao longo do tempo e para preservar relações, a mediação pode ajudar. Há casos em que partes diferem muito no poder de barganha, assim devem ser utilizados meios mais apropriados para proteção dos demandantes mais frágeis. Enfim, há que se ter uma leitura completa das variáveis envolvidas em cada conjunto de situações e buscar respostas que favoreçam mudanças globais e apropriadas para múltiplas conjunturas.

Dentre outras medidas cabíveis para fomentar o acesso à Justiça, CAPPELLETTI e GARTH (1988, p. 9-81) propõem que sejam efetuadas reformas dos procedimentos em geral, ainda que a tendência predominante siga na direção de buscar alternativas ao sistema tradicional para solução de conflitos. Nas estratégias alternativas salientam a criação de procedimentos mais simples e/ou julgadores mais informais, com especial preferência as técnicas que envolvam tipos particulares de causas, buscando a especialização das instituições e dos procedimentos. Todavia, para o resultado ser satisfatório, não basta criar especialização (principalmente para casos pequenos), é preciso simplificar o procedimento para não cair no problema da complexidade, dispêndio de recursos elevados e morosidade.

Por último, os autores revelam a preocupação no que toca as limitações e riscos do enfoque de acesso à Justiça chamando a atenção para o fato de que as modificações dos órgãos e instituições não substituem as reformas políticas e sociais, imprescindíveis para uma efetiva prestação da Justiça e mesmo as alterações provocadas por uma especialização podem resultar numa proliferação das demandas e julgadores especializados podem ficar acomodados e perder a visão do todo, além disso, pode ocorrer um enfraquecimento das garantias processuais fundamentais, o que representaria uma perda irreparável na qualidade da Justiça prestada.

Estas sugestões precisam entrar na agenda política de reformulação dos procedimentos judiciais e administrativos, bem como nos mecanismos que compõem a dinâmica de acesso à Justiça, a fim de resultar em medidas que aprimorem o controle judicial de políticas públicas. 


\section{Assuntos/ temas dos casos apreciados pelo STJ relativos ao controle judicial de políticas públicas}

Tabela 01 - Levantamento dos assuntos/temas presentes nos acórdãos do STJ sobre controle judicial de políticas públicas entre os anos de 2011 e2014.

\begin{tabular}{|c|c|}
\hline Análise dos Assuntos/temas abordados nas decisões proferidas pelo STJ nosprocessos & Quantidade \\
\hline $\begin{array}{c}\text { - Saneamento básico } \\
\text { - Saúde (medicamento/SUS, leito rede privada/subsidiário, central abastecimento farmacêutica, } \\
\text { deficiência mental, internação UTI, suspensão remédios similares, leitos clínicos eUTI) }\end{array}$ & 02 \\
\hline - Segurança pública (superlotação presídio) & 08 \\
\hline $\begin{array}{c}\text { - Ambiental (obra construção usina resíduos sólidos, licenças hidroelétricas, licençaparcelamento } \\
\text { solo) }\end{array}$ & 02 \\
\hline - Previdenciário (pensão por morte para criança sob a guarda judicial, salário maternidade) & 02 \\
\hline - Deficiência física (vaga para concurso público) & 01 \\
\hline - Idoso (acesso à moradia) & 01 \\
\hline - Energia elétrica (expansão rural) & 01 \\
\hline - Obra pública (recuperação de barragem) & 01 \\
\hline - Educação (FIES, centro educacional condições precárias, ação afirmativa cotas universidade) & 05 \\
\hline - Telecomunicações (universalização por interconexão, comunicaçãotelefônica/tarifa \\
interurbano) & 04 \\
\hline $\begin{array}{c}\text { - Improbidade administrativa (irregularidades verbas federais para implementaçãopolíticas } \\
\text { públicas/construção habitação popular) }\end{array}$ & 01 \\
\hline
\end{tabular}

Os assuntos abordados nos julgados proferidos pelo STJ sobre controle de políticas públicas (31 julgados entre 2011 e 2014) são de naturezas múltiplas e incluem os temas enunciados na tabela acima. A multiplicidade temática denota a abundância de políticas públicas que requerem atenção nos diversos níveis do Estado. Os tipos de política tratadas são distributivas, redistributivas, regulatórias e constitutivas. As políticas públicas levantadas tanto envolvem dimensões com maior ou menor exigência técnica na sua condução e com uso de recursos diferenciados, alguns de necessidade contínua, outros como investimento em infraestruturas.

Os pormenores, sejam na fase de construção da agenda, da implementação, ou da avaliação das políticas públicas escapam, em sua maioria, da análise empreendida pelo Poder Judiciário, destituído de capacidade institucional para adentrar nestas esferas, mas habilitado para atuar frente às questões dedireito.

A tabela revela que há uma predominância de temas relacionados às políticas públicas na área de saúde e educação, contudo em ambos os casos, temos uma indiscutível abundância temática interna sobre as questões suscitadas nos julgados analisados.

Isto, de certa forma reflete a própria complexidade das políticas públicas nestas áreas e a dificuldade de construir agendas, implementar ações e fazer avaliações que contemplem tantas frentes de ação e tantos atores operando em níveis setoriais distintos e que também sejam medidas transversais nos entes federativos. A Administração Pública e os Legisladores se veem diante de desafios em consolidar instrumentos que conformem 
escolhas entre universalidade e focalização, estabelecimento de prioridades, definição dos meios mais apropriados para alcançar os objetivos, procederem a ajustes e avaliar resultados.

A constância de casos envolvendo políticas públicas sobre saúde e educação pode indicar a maior visibilidade e relevância que estas matérias alcançam perante a sociedade e, que por serem temas sensíveis ao cotidiano das pessoas, são objetos de maiores cobranças junto aos poderes do Estado. O estatuto desses direitos sociais na Constituição como direitos fundamentais corrobora para mensuração de direitos subjetivos deles decorrentes e contribui para a busca de mecanismos judiciais para lhes garantir a eficácia.

Muito embora se tenha clareza da abundância de atores envolvidos e a complexidade das matérias tratadas nas questões concernentes às políticas públicas, chama a atenção o fato de que numericamente o volume de processos é pequeno no período analisado e, mesmo que se considere um espaço temporal maior (1988 a 2014), na pesquisa pronta do STJ figuram apenas 86 casos. Apesar desta representação não indicar a frequência da matéria no judiciário brasileiro, denota que o Poder Judiciário tem uma presença crescente, porém ainda diminuta nesta alçada. $\mathrm{O}$ que se percebe é que o debate doutrinário ganhou força e caráter polêmico muito maior do que a proporção de sua frequência em litígios nos quadros superiores do Judiciáriobrasileiro.

\section{Argumentos teóricos presente nas ações sobre controle judicial de políticas públicas julgadas pelo STJ}

Tabela 2 - Levantamento dos argumentos teóricos nos acórdãos sobre controle judicial de políticas públicas julgados pelo STJ, entre 2011 e2014.

\begin{tabular}{|c|c|}
\hline Análise dos argumentos teóricos utilizados nas decisões proferidas pelo STJ nos processos & $\begin{array}{l}\text { Quantidade de } \\
\text { menções }\end{array}$ \\
\hline - Técnica hermenêutica da ponderação de valores & 04 \\
\hline - Reserva do possível & 13 \\
\hline - Mínimo existencial & 07 \\
\hline - Questão orçamentária/escassez de recursos & 07 \\
\hline - Discricionariedade administrativa & 15 \\
\hline $\begin{array}{c}\text { - Dimensão principiológica (Teoria dos princípios) (Ex: dignidade pessoa humana; } \\
\text { segurança jurídica; legalidade; igualdade etc.) }\end{array}$ & 12 \\
\hline - Separação de poderes & 09 \\
\hline $\begin{array}{l}\text { - Admissão controle judicial de políticas públicas em casos excepcionais (Ex: paraassegurar } \\
\text { direitos constitucionais essenciais ou em caso de inescusável omissão estatal) }\end{array}$ & 10 \\
\hline $\begin{array}{c}\text { - Admissão controle judicial dos atos administrativos (Ex: ilegalidade, ausência de } \\
\text { proporcionalidade e/ou razoabilidade) }\end{array}$ & 07 \\
\hline - Ativismo judicial & 01 \\
\hline - Preponderância interesse coletivo sobre oindividual & 03 \\
\hline - Justiça distributiva & 01 \\
\hline - Igualdade (Ex: substancial, isonômica) & 03 \\
\hline - Improbidade administrativa & 01 \\
\hline
\end{tabular}




\begin{tabular}{|c|c|}
\hline - Referências a relatórios técnicos (Ex; área de saúde, telecomunicações) ou fontes \\
econométricas & 04 \\
\hline - Referência a Tratados Internacionais de Direitos Humanos & 01 \\
\hline - Ausência alegações teóricas & 02 \\
\hline - Votos vencidos & 02 \\
\hline
\end{tabular}

A tabela acima contendo os argumentos teóricos que compõem o panorama do fundamento das decisões proferidas pelo STJ sobre controle de políticas públicas (31 julgados entre 2011 e 2014) não tem a pretensão de franquear afirmações generalistas que indiquem uma tendência de comportamento argumentativo do Poder Judiciário como um todo ou mesmo tratar a questão como se não fosse contingencial e sujeita ao espaço e tempo retratado na análise. Portanto, desde já advertimos sobre os limites do exame efetuado, situando-os tão somente no quadro de decisões proferidas pelo STJ indicadas em seu próprio sitio eletrônico sob o título de pesquisa pronta "controle judicial de políticas públicas", com o corte temporal entre os anos de 2011 e 2014.

Apesar destas restrições do estudo ao campo de sua abrangência espacial e temporal, não se pode deixar de sublinhar que os dados coletados correspondem ao Tribunal Superior do Judiciário brasileiro habilitado a receber recursos provenientes de todo país e também julgar em primeira linha, alguns casos de sua competência originária, além de revelar atualização, uma vez que considera os casos julgados pelo STJ sobre controle de políticas públicas nos três últimos anos.

Uma segunda advertência a ser feita previamente consiste em informar que a tabela reflete a interpretação dos julgados feita neste estudo, podendo, eventualmente, haver uma divergência classificatória dos dados, numa situação em que estes venham a ser objeto de estudos por outro pesquisador. Além do que, estes argumentos colacionados na tabela, em regra, aparecem concomitantemente nos julgados, sendo certo que apenas se pretendeu registrar a constância dessas aparições nos casos analisados.

Uma terceira nota a ser feita diz respeito ao fato de que no levantamento dos dados contidos nos acórdãos procuramos não tecer juízo de valor sobre a assertividade das decisões pronunciadas pelo STJ e nem, tampouco, tomar partido nesta ou naquela forma de fazer o enquadramento dos argumentos coletados, posto que estes podem ser situados numa linha tanto de adesão pela positiva ou de rejeição pela negativa, conforme o caso. Por isso, fez-se a opção por indicar termos abertos e imparciais de aferição tais como: separação de poderes; mínimo existencial; discricionariedade administrativa etc. 
Diagnóstico do arcabouço teórico prevalecente nas decisões analisadas

Feitos os avisos preliminares, a avaliação procedida nos acórdãos estudados sugere uma tendência argumentativa nos julgados do STJ em matéria de controle judicial de políticas públicas que revela a preponderância de elementos de construções teóricas baseadas noneoconstitucionalismo.

O modelo neoconstitucionalista representa um marco de conversão do approach do direito no plano interno, com uma abertura maior para a dimensão axiológica, repetidamente repudiada pelo paradigma positivista que consagra a cientificidade jurídica, separando o direito dos valores. A inovação no neoconstitucionalismo dimana da aceitação da normatividade dos princípios, notadamente do princípio da dignidade da pessoa humana, compreendido como uma fonte de normatização e justificação das decisõesjurídicas.

Tal mudança de ponto de vista ressoa diretamente na questão dos direitos sociais - em relação a estes direitos prevalece grande parte das querelas abarcadas no controle judicial de políticas públicas -, na medida em que estes são entendidos como imprescindíveis para a realização da dignidade da pessoa humana na plenitude das suas capacidades, percebidas como inseparáveis e interdependentes dos direitos deliberdade.

A separação instituída no positivismo jurídico entre direito e política, direito e valores, Estado e sociedade, é relativizada pelo paradigma pós-positivista, no qual se coloca o neoconstitucionalismo. A atividade interpretativa não invalida, antes passa a exigir que sejam feitas escolhas valorativas de caráter político, moral etc.

Neoconstitucionalismo é uma terminologia empregada doutrinariamente para identificar a condição do constitucionalismo contemporâneo que, à semelhança do positivismo jurídico, é um fenômeno complexo, heterogêneo, todavia, concorrente ou contraposto ao positivismo no seu sentido ideológico, metodológico e teórico (PECES-BARBA, 1999, p. 83 ss). ${ }^{5}$

Em suma, o neoconstitucionalismo consiste num conjunto vasto de transformações sobrevindas tanto no domínio dos Estados, como também do direito constitucional, em meio às quaisassinala-se:

1. Como marco histórico - a origem do Estado constitucional de direito, cuja consolidação se sucedeu ao longo das últimas décadas do século XX;

2. Como marco filosófico - o pós-positivismo, com a centralidade dos direitos humanos fundamentais e a reaproximação entre direito e a dimensão axiológica;

3. Como marco teórico - o conjunto de transformações que abrangem a força normativa da constituição e o incremento de uma nova hermenêutica constitucional.

\footnotetext{
${ }^{5} \mathrm{O}$ presente momento afirma-se como uma etapa de transição, não parecendo ser adequado sustentar posições no sentido de afirmar o ocaso do positivismo e de suas variações, diante do primado do neoconstitucionalismo. Muitos doutrinadores ainda defendem o positivismo jurídico e percebem as alterações como parte de uma remodelação interna do positivismo, uma espécie de positivismo corrigido. Cf. PECES-BARBA, Gregório Martinez. Derechos sociales y positivismo jurídico. Madrid: Dykinson, 1999, p. 83 ess.
} 
Algumas noções centrais do neoconstitucionalismo podem ser descritas em quatro fenômenos (ARBALLO, 2007):

1. Novos textos constitucionais - constituições inovadoras ou reformadas, com disposições de direitos sociais; mais garantias institucionais; inserção de conceitos e valores inscritos em forma deprincípios;

2. Consensos renovados - abalizados na conscientização do valor vinculante dos direitos humanos, no contágio axiológico do positivismo jurídico e no desenvolvimento da influência do direito comparado, favorecida em parte pelo processo de globalização;

3. Teorias inovadoras - modelos mais filosóficos (DWORKIN, 2002 e HABERLE, 1997, 2002) e outros mais juridicistas (ALEXY, 1999 e ZAGREBELSKY, 2002), utilizados pelos juristas com o escopo de aguçar a força normativa da constituição;

4. Jurisprudência revigorada - jurisprudência com inclinação no sentido de admitir: a constituição como norma (força normativa da constituição); a interpretação expansiva da abrangência dos direitos constitucionais básicos; e o acionamento de direitos latentes ou garantias qualificadas como negativas (CARBONELL, 2002 e FERRAJOLI, 2002).

Para BARCELLOS (2004, p. 44-72 e 2006, p. 31-60), são características particulares do neoconstitucionalismo do ponto de vista metodológico-formal:

1. Normatividade da constituição - percepção de que as normas constitucionais são normas jurídicas imbuídas de imperatividade;

2. Ascendência constitucional sobre toda a ordem jurídica como efeito natural da rigidezconstitucional;

3. Centralidade da constituição nos sistemas jurídicos, entendendo que todos os ramos do direito devem ser interpretados e aplicados em concordância com as disposições constitucionais.

Os atributos do neoconstitucionalismo do ponto de vista material são:

1. A inclusão de valores e opções políticas nos textos constitucionais, com relevo para a dignidade da pessoa humana;

2. A ampliação de conflitos originados pelas opções normativas e filosóficas, muitas vezes conflitantes no sistema constitucional. Desde o momento em que valores e opções políticas tornaram-se normas jurídicas, nasceu a obrigação de erigir uma dogmática capaz de promover a eficácia jurídica destas normas (BARCELLOS, 2006, p. 31-60).

O neoconstitucionalismo ocasionou uma conversão de modelo de aplicação judicial do direito, pois o padrão de juiz civil, a-político, imparcial e funcionalizado, que aplica um direito previamente estatuído, sem arguir a legitimidade do conteúdo das leis e detentor de um saber que elimina a responsabilidade; transpõe-se para uma nova racionalidade, que transita da condição cognitiva-instrumental para um tipo de racionalidade finalística, 
fundamentada numa categoria de juiz que afere e assume a responsabilidade pelos resultados ou efeitos sociais das suas decisões.

A interpretação axiológica da constituição tem duas facetas: por um lado, acolhe a necessidade de justiça substancial, entretanto, por outro lado, dá espaço para um direito mais incerto, menos preciso, porque passa por uma seleção dos valores considerados prevalecentes para a resolução do casoconcreto.

O desafio do neoconstitucionalismo consiste em evitar que a principialização do direito e a interpretação axiológica dela resultante, ocasione riscos para a previsibilidade e a segurança jurídica. O processo decisório não deve pautar-se em casuísmos, porquanto isto poria em xeque a função ordenatória do direito.

O neoconstitucionalismo é enlevado como um conjunto formado por uma multiplicidade de juízos que sobrepujam o legalismo estrito do positivismo normativista, sem cair na fundamentação de razão subjetiva do jusnaturalismo. O marco deste modelo pode ser vislumbrado na elevação dos valores, no reconhecimento da normatividade dos princípios e na importância adjudicada aos direitos fundamentais. O neoconstitucionalismo é um dos grandes responsáveis pela reintrodução do debate da ética no Direito. São dados dessa renovação teórica, filosófica e prática no Direito: o pluralismo político e jurídico, a nova hermenêutica e a ponderação de interesses.

Todavia, é preciso acolher que o direito constitucional e a teoria da Constituição particularmente, têm possibilidades e limites. Os otimismos exagerados sofrem da enfermidade de um olhar muitas vezes desconectado ou não completamente integrado e crítico em relação ao complexo universo social. Cabe recordar o lembrete feito por Luís Roberto Barroso: "O constitucionalismo, por si só, não é capaz de derrotar algumas das vicissitudes que têm adiado a plena democratização da sociedade brasileira. (O Direito tem seus limites e possibilidades, não sendo o único e nem sequer o melhor instrumento de ação social) " (BARROSO, 2003, p.44).

Enfim, da análise procedida nos acórdãos proferidos pelo STJ em disciplina de controle judicial de políticas públicas entre os anos de 2011 e 2014, chamou-nos a atenção o fato de que em nenhum dos julgados encontramos qualquer referência teórica que ultrapassasse a vertente neoconstitucionalista ou que utilizasse outros fundamentos teóricos complementares nas decisões, prevalecendo uma dimensão mais ativista de atuação judicial e menos dialógica ou institucionalista quanto aos problemas originados no campo das políticas públicas e os desdobramentos face aos poderes executivo elegislativo.

Sem a pretensão de trazer uma resposta conclusiva sobre o motivo da preferência por tal arcabouço teórico, sendo este, inclusive, um limite do próprio levantamento realizado no estudo, sugerimos que esta opção pode ser consequência do alinhamento com os principais postulados neoconstitucionalistas, auxiliado pela própria instrumentalidade operacional para efeito de decisão, resultante do uso de conceitos já naturalizados no meio jurídico e amplamente tratados na doutrina, o que traz uma comodidade satisfatória para efeito da prestação 
jurisdicional, bem como potencialmente aproximar o judiciário do cidadão reduzindo seu déficit de legitimidade pela ausência do crivo da soberania popular.

Contudo, esta escolha firmada no tempo com algum grau de continuidade pode ser um sinalizador de uma leitura que, aos poucos, pode tornar-se desatualizada face às renovações dos olhares da doutrina sobre um tema sempre tão tenso na relação entre os poderes e suas capacidades institucionais. Fica o alerta de que a leitura positivista tradicional e a pós-positivista já não respondem com exclusividade sobre o tema do controle judicial de políticas públicas e o judiciário nas suas cortes maiores não pode se imiscuir de periodicamente revisar suas balizes orientadoras, especialmente em tempo de aceleradas mudanças experimentadas nasociedade.

\section{Dimensão princípiologica}

Nos acórdãos do STJ analisados há, com alguma tenacidade, a referência ao caráter principiológico ${ }^{6}$, sugerindo como princípio maior de referência o princípio da dignidade de pessoa humana, mas também com aportes aos princípios da segurança jurídica, da legalidade e da igualdade. Em regra, a arguição baseada nos princípios segue acompanhada com a preocupação em torno da eficácia dos comandos constitucionais, primando pela concretização das normas imbuídas de aspectos axiológicos.

A teoria salienta que a normatividade dos princípios compreendidos como mandatos de otimização (Robert Alexy) tem particular relevância para os direitos fundamentais, sobretudo o princípio da dignidade da pessoa humana que cumpre a função de vetor e gerador de regras relativas aos mencionados direitos.

Uma definição precisa do princípio da dignidade da pessoa humana não é viável, porquanto é um conceito vago e impreciso e de conteúdo polissêmico. Todavia, nos julgados examinados é plausível sua identificação como uma categoria axiológica aberta, sendo impróprias conceituações de maneira fixa, ainda mais quando verificado que uma definição desta natureza não se harmoniza com o pluralismo e a diversidade de valores manifestos nas sociedades democráticas contemporâneas (CANOTILHO, 2003, p. 219 e SARLET, 2001, p. 105).

Nos julgados avaliados, o princípio da dignidade humana geralmente é conexo com a noção de mínimo existencial, encarado como o aspecto material da dignidade.

\footnotetext{
${ }^{6}$ Em poucas palavras, a Teoria dos Princípios tem fundamento na classificação das normas constitucionais como regras e princípios e sustentando a importância do aspecto axiológico dos princípios e a necessidade de concretizá-los, como forma de reconhecimento da força normativa da Constituição.
} 


\section{Mínimo existencial}

O mínimo existencial constitui um conjunto de prestações e garantias asseguradas aos indivíduos e comunidades, que são indispensáveis para a sua existência e de sua família em condições dignas. É um primeiro degrau na escada do desenvolvimento, capaz de afastar a pessoa das condições indignas depobreza.

O mínimo existencial não tem dicção constitucional própria. Abrange qualquer direito considerado em sua dimensão essencial e inalienável. Não é mensurável, por envolver mais os aspectos de qualidade que de quantidade, o que torna difícil estremá-lo, em sua região periférica, do máximo de utilidade, que é princípio ligado a ideia de Justiça e de redistribuição da riqueza social (TORRES, 2001, p.266).

As formulações sobre o mínimo existencial expressam uma vertente garantística e uma vertente prestacional. A feição garantística impede agressão do direito, isto é, requer cedência de outros direitos ou de deveres (pagar imposto, p. ex.) perante a garantia de meios que satisfaçam as mínimas condições de vivência digna da pessoa ou da sua família. Neste aspecto o mínimo existencial vincula o Estado e o particular.

Há muita discussão em torno da definição qualitativa e quantitativa das prestações e meios de concretização do mínimo existencial. Um dos problemas em relação ao aspecto prestacional consiste em determinar quais prestações de direitos sociais conformam o seu núcleo. Caso se chegue a um ponto de convergência neste aspecto, ainda assim perdurará a dificuldade de saber em relação a cada direito em particular qual a extensão da obrigação do Estado de prover ou satisfazer a necessidade ou interesse social ou econômico tutelados pelo direito. Quando um determinado direito social é reconhecido a certas pessoas ou grupos em uma determinada medida, fica a dúvida sobre a possibilidade de estabelecer juízos de comparação entre a situação dos beneficiários, controlando a legalidade e razoabilidade do fator de diferenciação utilizado pelo Estado ao prover, garantir ou promover seletivamente os interesses tutelados pelo direito.

Enfim, a questão do mínimo existencial suscita controvérsias como, por exemplo, a conceituação, a identificação das prestações indispensáveis para a manutenção de uma vida digna, a função do Estado na promoção e proteção do mínimo existencial, dentre outros. Tais questionamentos passam a margem dos fundamentos argumentativos colacionados nas decisões proferidas pelo STJ submetidas ao nosso exame e ficam encobertos entre conceitos naturalizados tão comuns no universojurídico.

\section{Disciplina orçamentária e escassez de recursos}

A necessidade do Direito resulta da escassez relativa aos bens, ao exigir critérios de repartição, não derivados das regras de economia, mas daqueles que supõem razões morais assumidas pelo poder e transladadas à 
organização da vida social. A escassez amplia sua incidência sobre o jurídico, estendendo-a a aspectos de validade, de justificação da existência mesma do Direito, como também as dimensões de justiça e de eficácia.

Em regra, foi possível observar na estruturação dos julgados a compreensão em torno da não oponibilidade da reserva da possível frente mínima existencial, exceto nas situações em que o ente público pudesse comprovar a inexequibilidade do direito social por absoluta insuficiência de caixa.

Outro entendimento que se adicionava com alguma regularidade a este, diz respeito à apreciação de que a ausência de previsão orçamentária não afastava a obrigação de garantir o mínimo existencial. Portanto, a tendência decisória assinalava para a mitigação dos argumentos em torno da reserva do possível e da necessidade de previsão orçamentária para suportar os gastos demandados em determinada política pública.

\section{Reserva do possível}

A escassez de recursos conduz a argumentação em torno da reserva do possível. A expressão reserva do possível procura identificar o fenômeno econômico da limitação dos recursos disponíveis diante das necessidades quase sempre infinitas a serem por eles supridas. A reserva do possível significa que, para além das discussões jurídicas sobre o que se pode exigir judicialmente do Estado e, em última análise, da sociedade, já que é esta que o sustenta, é importante lembrar que há um limite de contingência material para esses direitos. Em suma, pouco prospera do ponto de vista prático, a previsão normativa ou a refinada técnica hermenêutica se não houver recursos para custear as despesas geradas por determinados direitos subjetivos (BARCELLOS, 2002, p. 236).

O tema da reserva do possível, embora não tenha recebido atenção específica da doutrina brasileira até a década de 90, não era totalmente desconhecido. Suas aparições mais comuns relacionavam-se com os limites dos direitos sociais, tradicionalmente considerados como direitos positivos, isto é, direitos que demandavam ações do Estado, que, por sua vez, custavam dinheiro. Na ausência de um estudo mais aprofundado, a reserva do possível funcionou muitas vezes como um argumento absoluto, interferindo no avanço na sindicabilidade dos direitos sociais. A iminência do terror econômico, anunciada tantas vezes pelo Poder Executivo, cuidava de reservar ao Poder Judiciário o papel de vilão nacional, caso determinadas decisões fossem tomadas (BARCELLOS, 2002, p. 237).

A cláusula da reserva do possível só se justifica quando aferida em face de motivo razoável que desculpe a autoridade, de forma fundamentada e ampla (comprovada), em processo próprio, com transparência e contraditório, da impossibilidade de cumprir com o estabelecido. Todavia, em contrapartida, a administração se sujeita, em regra, a determinação de proibição de retrocesso, no que tange aos direitos econômicos, sociais e culturais, de maneira que não pode reduzir o âmbito de incidência alcançado na concretização destes direitos, a menos em casos fundamentados e comprovados que justifiquem a medidarestritiva. 


\section{Separação de Poderes}

Uma das objeções mais recorrentes ao fenômeno de judicialização da política situa-se na defesa de que o processo conduz a fratura da separação dos Poderes, tendo em vista que o Poder Judiciário, através de suas decisões, atinge o Poder Legislativo, através do controle de constitucionalidade ou pelo exame ou reexame de atos afeitos a sua competência (p. ex: exames dos atos das Comissões Parlamentares de Inquérito, dos processos de cassação de parlamentares por falta de decoro), e também atinge o Poder Executivo, através do controle judicial dos atos administrativos, principalmente das políticas públicas.

A separação de poderes progressivamente sofreu complexificação e o seu tratamento dogmático ganhou cercanias mais densas. O perfil contemporâneo do princípio da separação de Poderes desautoriza qualquer mensuração do mesmo em modo absoluto, ou seja, para designar uma total separação. O controle do poder foi o objetivo principal, o fundamento de toda essa construção e não pode ser esquecido ou abandonado em nome de concepções meramente dogmáticas. Entretanto, não se pretende afirmar que qualquer intervenção proveniente do Poder Judiciário, acobertada com o suposto manto de controle, seja devida ou mesmo necessária, pois podem ocorrer excessos.

Os limites entre controle e invasão de competência nem sempre são muito claros e as dificuldades perduram em estabelecer até onde o Poder Judiciário pode exercer o controle dos atos de Governo sem exacerbar suas funções. Contudo, também não é correto utilizar o princípio da separação de Poderes como um instrumento inviabilizador do controle do Poder Judiciário sobre as políticas públicas sob a alegação de que acarretaria uma indevida judicialização da política, principalmente quando o exame procedido pelo Judiciário tem por propósito conferir a compatibilidade dos atos com as normas constitucionais que vinculam todos os poderes, inclusive a Administração. Há que se buscar a moderação, o equilíbrio na atuação dos três Poderes, apesar de se reconhecer a presença de inúmeros obstáculos para alcançar tal finalidade.

Nos acórdãos analisados pronunciados pelo STJ verificou-se a tendência na compreensão de que a separação de poderes não pode oferecer óbice aos direitos fundamentais. Contudo, também se detectou fundamentação diversa, segundo a qual a separação de poderes e as regras de caráter orçamentário e financeiro para a atuação do ente público impõem limites à atuação do Poder Judiciário, cuja performance somente se justificaria diante da falta de razoabilidade ou abuso, caracterizando uma injustificável inércia estatal, sendo vedada a invasão do Poder Judiciário no cerne da discricionariedade política reservada ao Governo competente para exercer esta ou aquela atividade, por ofender a separação dos poderes. 


\section{Discricionariedade administrativa e controle dos atos administrativos}

A discricionariedade consiste em certa margem de liberdade, expressa no conteúdo do ato praticado pelo administrador, no cumprimento estrito da lei, que decorre da hipótese prevista na norma, e/ou no comando nela inserido e/ou na finalidade por ela pretendida. Nestas situações cabe um juízo subjetivo do administrador no que diz respeito:

1. À determinação ou reconhecimento, dentro de certos limites, da situaçãofática;

2. Ao agir ou não agir;

3. À escolha do momento para fazê-lo;

4. À forma jurídica do ato;

5. À escolha de medida considerada adequada, perante a situação de fato, para cumprir a finalidade legal (BANDEIRA DE MELLO, 1998, p. 17)?

Nos acórdãos do STJ analisados se notou a tendência de compreensão de que a Administração não dispõe de discricionariedade frente aos direitosfundamentais.

\section{Admissão do controle judicial de políticas públicas em casos excepcionais e/ou admissão do controle judicial dos atos administrativos}

Conexo com as problematizações em torno da discricionariedade administrativa e da separação de poderes situa-se a discussão sobre a admissão do controle judicial de políticas públicas e/ou atos administrativos.

Os acórdãos estudados trazem a orientação no sentido de acolher a hipótese do controle judicial de políticas públicas em casos excepcionais, para assegurar direitos constitucionais essenciais (direitos fundamentais), tais como o direito à saúde, devido a sua inegável ligação com o direito à vida e pela afetação ao mínimo existencial ou, também, nas hipóteses de omissão estatalinescusável.

As políticas públicas se sujeitam a controle de constitucionalidade e legalidade, nomeadamente quando o que se tem não é exatamente o exercício de uma política pública qualquer, porém a sua completa ausência ou o cumprimento meramente perfunctório ou insuficiente.

Em relação aos atos administrativos em geral, figura a compreensão de que ao Poder Judiciário não é vedado debater o mérito administrativo. Se a Administração deixar de se valer da regulação para promover

\footnotetext{
${ }^{7}$ BANDEIRA DE MELLO, Celso Antônio. Op. Cit., p. 17. Nas suas palavras: "A discrição administrativa pode residir na hipótese da norma, no caso de ausência de indicação explícita do pressuposto de fato ter sido descrito através de palavras que recobrem conceitos vagos, fluidos ou imprecisos. Pode residir no comando da norma, quando nele se inculca ao administrador certa margem de liberdade para decidir-se se pratica ou se não pratica dado ato e em que momento o faz ou mediante que forma jurídica o revestirá ou, ainda, que ato pratica diante daquelas situações fáticas. Finalmente, pode residir na finalidade da norma, pois, como ela serve de diretriz para a intelecção dos demais elementos da estrutura lógica da norma, se a finalidade é um valor - como deveras o é - e se os valores não são unissignificativos, a fluidez da finalidade reflui sobre o pressuposto de fato."
} 
políticas públicas, proteger hipossuficientes, garantir a otimização do funcionamento do serviço concedido ou assegurar o funcionamento em condições de excelência, tanto para o fornecedor/produtor como, principalmente, para o consumidor/usuário, haverá vício ou flagrante ilegalidade a abonar a intervenção judicial.

\section{Ponderação de valores}

Em alguns poucos acórdãos do STJ sobre controle judicial de políticas públicas ocorrem mensurações sobre pesos atribuídos aos princípios em colisão envolvendo casos como princípio da dignidade da pessoa humana versus princípio da separação de poderes; princípio da igualdade versus princípio da segurança jurídica; sendo nestes casos utilizada a ponderação de valores para solucionar os casos numa conjuntura de orientação neoconstitucionalista.

\section{Aspectos gerais}

Em poucos julgados do STJ o Poder Judiciário recorreu a suportes provenientes de relatórios técnicos para subsidiar as decisões em casos cuja especificidade do tema em discussão dava espaço para um aprofundamento da matéria por especialistas na área. Destaque para quatro acórdãos cuja discussão teve a participação de agências reguladoras ANATEL e ANVISA. Mesmo que a complexidade das políticas públicas caracterize este campo de estudo e não apenas das matérias de políticas públicas provenientes de agências reguladoras, o Poder Judiciário revela uma tendência em admitir o caráter mais técnico e de munir-se de elementos desta natureza apenas nas questões que versam sobre temáticas presentes nas agendas das agências reguladoras.

Quando a questão de fundo a ser considerada para decisão envolve direitos fundamentais, geralmente há uma inclinação para soluções embasadas meramente no campo jurídico, sem se considerar necessário recorrer a relatórios técnicos ou elementos adicionais de instrução, que apontem possíveis pontos a serem considerados no caso e que incidam no processo, em si mesmo, de estruturação/desenvolvimento da política pública questionada. O que chama a atenção é que as políticas públicas comportam um grau de complexidade na formulação, implementação e avaliação, elementos estes que, em regra, não são devidamente apreciados no exercício do controle judicial e que podem ocasionar algumas distorções nas medidas propostas.

Outro ponto a ser sublinhado na análise procedida é a quase ausência de referências aos Tratados Internacionais de Direitos Humanos nas decisões proferidas pelo STJ (apenas um caso), muito embora, grandes partes das matérias submetidas ao seu exame tenham normatizações desta natureza. Apesar da omissão destas referências normativas internacionais não há uma fragilização da decisão proferida por consequência, mas pode 
eventualmente indicar um descaso frente ao Direito Internacional dos Direitos Humanos e suas possíveis contribuições para as matérias analisadas.

Por último, sublinhamos que praticamente não existem nos julgados do STJ aferidos menções que revelem uma linha no campo da Teoria da Justiça que possa servir de suporte direto as decisões proferidas (apenas um caso e sem maiores aprofundamentos). A instrumentalidade, o tecnicismo e o formalismo jurídico são percebidos como elementos suficientes para fundamentar as decisões e a orientação preferencial é pelo minimalismo na construção das sentenças.

\section{CONCLUSÃO}

O levantamento e análise das ações sobre controle judicial de políticas públicas julgadas pelo STJ entre os anos de 2011 e 2014 nos permitiram concluir que a temática das políticas públicas não passa despercebida pelo Poder Judiciário. Antes, a pesquisa revelou uma efetiva preocupação, por parte do STJ, em dar concretude aos direitos sociais consubstanciados em políticas públicas, geralmente em matéria de direitos sociais.

A base teórica que serviu de arcabouço para a arquitetura das decisões judiciais examinadas foi erguida sob os pilares da visão do neoconstitucionalismo, seguindo as orientações de buscar a força normativa da Constituição e vencendo posicionamentos tradicionais no campo do direito administrativo, que afastavam a possibilidade de controle judicial de políticas públicas.

Enfim, na análise dos julgados não encontramos qualquer referência teórica que ultrapassasse a vertente neoconstitucionalista ou que utilizasse outros fundamentos teóricos complementares nas decisões, prevalecendo uma dimensão mais ativista de atuação judicial.

Apesar do estudo não trazer uma resposta conclusiva sobre o motivo da preferência por tal arcabouço teórico, sugerimos que esta opção pode ser consequência do alinhamento com os principais postulados neoconstitucionalistas, amparado pela própria instrumentalidade operacional para efeito de decisão, fruto do emprego de conceitos já naturalizados no meio jurídico e amplamente tratados na doutrina, o que oferece comodidade para a tarefa de decidir, além de potencialmente servir para aproximar o judiciário do cidadão, através da redução de seu déficit de legitimidade originado pela ausência do crivo da soberania popular.

No entanto, a continuidade do uso deste recurso argumentativo para fundamentação das decisões pode ser um sinalizador de uma leitura que, aos poucos, tende a se tornar desatualizada frente às renovações dos olhares da doutrina no que concerne à relação entre os poderes e suas capacidadesinstitucionais.

A leitura positivista tradicional e a pós-positivista não são as únicas formas de conduzir o debate sobre o tema do controle judicial de políticas públicas e o judiciário, nas suas cortes maiores, deve ter sempre a 
preocupação de revisar os fundamentos de suas decisões, assumindo a necessidade de construir diálogos interdisciplinares e apropriados para tempos de rápidas mudanças nasociedade.

\title{
EMPIRICAL PERCEPTIONS ABOUT JUDICIAL CONTROL IN POLICY
}

\begin{abstract}
This article deals with the mapping empirical aspects about the performance of the Superior Court of Justice (STJ) in the exercise of judicial policy, seeking to do a concise diagnosis of the state of the art within the judiciary. The methodology consisted of survey and empirical analysis of the STJ judged cataloged as ready research on "judicial control of policies" between the years 2011 and 2014, building the database from the examination of decisions and seeking the theoretical bias that served for underlies them, which delineated profile is preferably marked by neoconstitucionalista theoretical matrix.
\end{abstract}

Keywords: judicial, policy, empirical analysis, neoconstitutionalism, Superior Court of Justice (Brazil).

\section{REFERENCIAS}

ALEXY, Robert. Teoría de los derechos fundamentales. Madrid: Centro de Estudios Constitucionales, 1999.

ARBALLO, Gustavo. “Un constitucionalismo expandido”. Revista Evocati. (www. evocati.com.br). n. 13, jan. 2007.

BANDEIRA DE MELLO, Celso Antônio. Discricionariedade e controle jurisdicional. 2a ed. São Paulo: Malheiros, 1998.

BARCELlOS, Ana Paula de. A eficácia jurídica dos Princípios Constitucionais: O Princípio da Dignidade da Pessoa Humana. Rio de Janeiro: Renovar, 2002.

"Neoconstitucionalismo, direitos fundamentais e controle das políticas públicas". In: SARMENTO, Daniel; GALDINO, Flávio (orgs.). Direitos Fundamentais: estudos em homenagem ao Professor Ricardo Lobo Torres. Rio de Janeiro: Renovar, 2006, p. 31-60.

"O começo da história: a nova interpretação constitucional e o papel dos princípios no direito brasileiro." In: BARROSO, Luís Roberto (org.). A nova interpretação constitucional: ponderação, direitos fundamentais e relações privadas. Rio de Janeiro: Renovar, 2004, p.44-72.

BARROSO, Luís Roberto. Temas de direito constitucional. T. II. Rio de Janeiro: Renovar, 2003.

(org.). A nova interpretação constitucional: ponderação, direitos fundamentais e relações privadas. Rio de Janeiro: Renovar, 2004.

"Neoconstitucionalismo e constitucionalização do Direito: o triunfo tardio do Direito Constitucional no Brasil." Revista de Direito Administrativo. Rio de Janeiro. n. 240, 2005, p. 1-42.

CANOTILHO, José Joaquim Gomes. Direito Constitucional e teoria da Constituição. $7^{a}$ ed. Coimbra: Almedina, 2003, p.219. 
CAPPELLETTI, Mauro e GARTH, Bryant. Acesso à justiça. Porto Alegre: Fabris, 1988.

CARBONELL, Miguel. Neoconstitucionalismo. 2a ed. Madrid: Editorial Trotta, 2005.

COUTINHO, Diogo R. "O direito nas políticas públicas". In: MARQUES, Eduardo; FARIA, Carlos Aurélio Pimenta de. A política pública como campo multidisciplinar. São Paulo:UNESP; Rio de Janeiro: FIOCRUZ, 2013.

DWORKIN, Ronald. Levando os direitos a sério. São Paulo: Martins Fontes, 2002.

EMERIQUE, Lilian Balmant. "Exame jurisdicional de políticas públicas de direitos sociais e a judicialização da política”. Revista OAB/RJ: n. 2, v. 26, jul-dez 2010, p.53-80.

Neoconstitucionalismo e direitos sociais; um contributo para a luta contra a pobreza. Rio de Janeiro: Freitas Bastos/FAPERJ, 2009.

FARIA, José Eduardo (org.). Direitos humanos, direitos sociais e justiça. 1a ed. $2^{a}$ tiragem. São Paulo: Malheiros, 1998.

FERRAJOLI, Luigi. Derechos y garantias. 4a ed. Madrid: Trotta, 2004. Idem. Los fundamentos de los derechos fundamentales. $2^{\mathrm{a}}$ ed. Madrid: Trotta, 2005.

GRINOVER, Ada Pelegrini, DINAMARCO, Candido Range, e WATANABE, Kazuo (Coord.). Participação e Processo. Revista dos Tribunais: São Paulo, 1988.

HÄBERLE, Peter. Hermenêutica constitucional. A sociedade aberta dos intérpretes da Constituição: contribuição para a interpretação pluralista e "procedimental" da Constituição. Porto Alegre: Sergio Antonio Fabris, 1997.

Pluralismo y Constitución. Madrid: Tecnos, 2002.

MIRANDA, Jorge. Manual de direito constitucional. T. II. 5a ed. Coimbra: Coimbra, 2003

PALU, Oswaldo Luiz. Controle dos atos de governo pela jurisdição. São Paulo: Revista dos Tribunais, 2004.

PECES-BARBA, Gregório Martinez. Derechos sociales y positivismo jurídico. Madrid: Dykinson, 1999.

PIÇARRA, Nuno. A separação dos Poderes como doutrina e princípio constitucional. Coimbra: Coimbra, 1989.

SANTOS, Boaventura de Souza. A Judicialização da Política. Publicado no Público em 26 de Maio de 2003.

SAUCA, José Maria Sauca (org.). Problemas actuales de los derechos fundamentales. Madrid: Instituto de Derechos Humanos Bartolome de las Casas; Universidad Carlos II de Madrid; Boletín Oficial de Estado, 1994.

SARLET, Ingo Wolfgang. A eficácia dos direitos fundamentaist. 2a ed. Porto Alegre: Livraria do Advogado, 2001, p. 105.

SARMENTO, Daniel; GALDINO, Flávio (orgs.). Direitos Fundamentais: estudos em homenagem ao Professor Ricardo Lobo Torres. Rio de Janeiro: Renovar,2006 
TORRES, Ricardo Lobo. A cidadania multidimensional na era dos Direitos. In: TORRES, Ricardo Lobo. (Org.). Teoria dos Direitos Fundamentais. 2. ed. Rio de Janeiro: Renovar, 2001.

VIANNA, Luiz Werneck (org.). A democracia e os Três Poderes no Brasil. Belo Horizonte: UFMG, Rio de Janeiro: IUPERJ/FAPERJ,2002.

VALLINDER, T.; TATE, C. Neal. The global expansion of Judicial Power: The Judicialization of politics. New York: New York University, 1995.

WATANABE, Kazuo. O acesso à justiça e sociedade moderna, in GRINOVER, Ada Pelegrini, DINAMARCO, Candido Range, e WATANABE, Kazuo (Coord.). Participação e Processo. Revista dos Tribunais: São Paulo, 1988.

ZAGREBELSKY, Gustavo. El derecho dúctil. Madrid: Trotta, 2002.

Trabalhoenviadoem 19deagostode2015.

Aceitoem 15denovembrode2015. 